This item was submitted to Loughborough's Research Repository by the author.

Items in Figshare are protected by copyright, with all rights reserved, unless otherwise indicated.

\title{
Transparent icephobic coatings using bio-based epoxy resin
}

PLEASE CITE THE PUBLISHED VERSION

https://doi.org/10.1016/j.matdes.2017.12.017

\section{PUBLISHER}

(c) Elsevier

VERSION

AM (Accepted Manuscript)

\section{PUBLISHER STATEMENT}

This work is made available according to the conditions of the Creative Commons Attribution-NonCommercialNoDerivatives 4.0 International (CC BY-NC-ND 4.0) licence. Full details of this licence are available at: https://creativecommons.org/licenses/by-nc-nd/4.0/

\section{LICENCE}

CC BY-NC-ND 4.0

\section{REPOSITORY RECORD}

Wu, Xinghua, Shunli Zheng, Daniel A. Bellido-Aguilar, Vadim V. Silberschmidt, and Zhong Chen. 2019.

"Transparent Icephobic Coatings Using Bio-based Epoxy Resin". figshare. https://hdl.handle.net/2134/27985. 


\title{
Transparent icephobic coatings using bio-based epoxy resin
}

\author{
Xinghua $\mathrm{Wu}^{\mathrm{a}}$, Shunli Zheng ${ }^{\mathrm{a}}$, Daniel A. Bellido-Aguilar ${ }^{\mathrm{a}}$, Vadim V. Silberschmidt ${ }^{\mathrm{b}}$, Zhong Chen ${ }^{\mathrm{a}, *}$ \\ a School of Materials Science and Engineering, Nanyang Technological University, 50 Nanyang Avenue, 639798, Singapore \\ ${ }^{\mathrm{b}}$ Wolfson School of Mechanical Electrical and Manufacturing Engineering, Loughborough University, Loughborough, Leicestershire LE11 3TU, UK
}

\section{H I G H L I G H T S}

- Bio-based transparent icephobic coat-ings were formulated for room temper-ature processing.

- The addition of silanes enhanced the water repellency and reduces ice adhe-sion strength.

- The optimum coating exhibited ice ad-hesion around $50 \mathrm{kPa}$ at $-20^{\circ} \mathrm{C}$ and icing delay time of 2 min $45 \mathrm{~s}$.

- As a demonstration, ice accumulation was much reduced on wooden floor plates and panels.

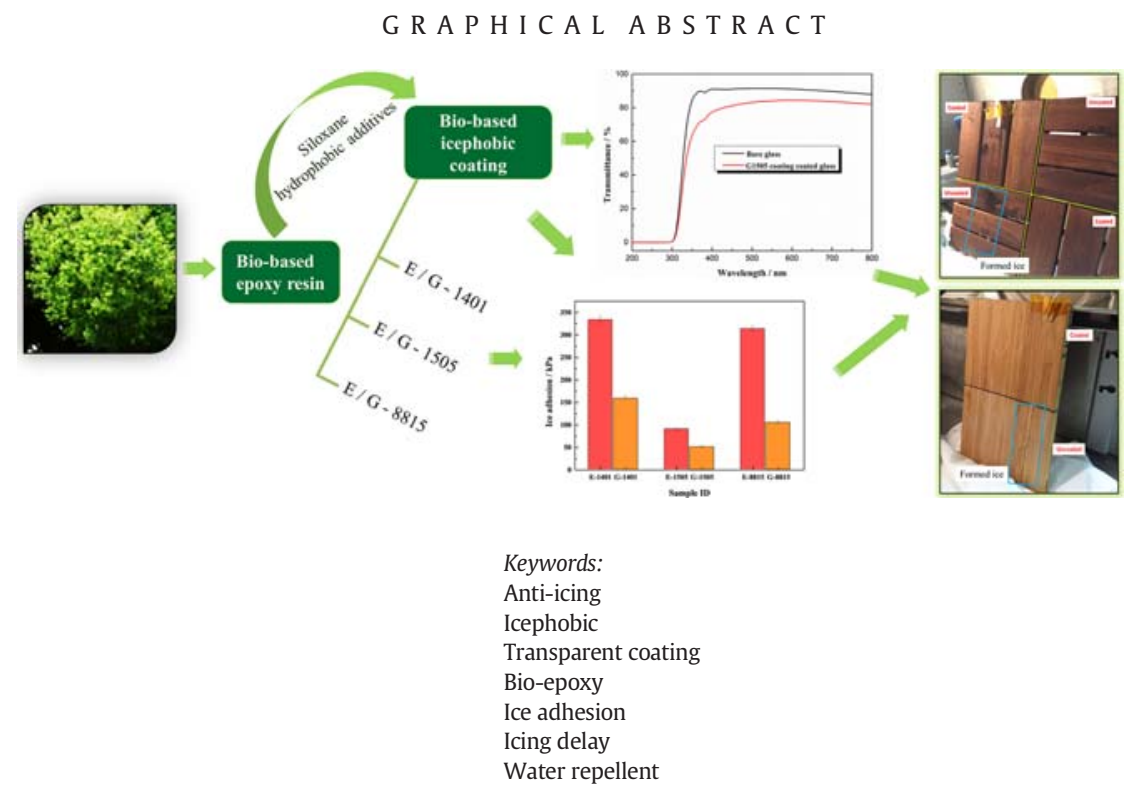

A B S T R A C T

Ice accretion and accumulation pose serious challenges for maintaining the operation and performance of outdoor facilities in cold climate. Epoxy resin, with a wide range of formulation possibilities, is widely used as protective coatings for outdoor facilities. However, bisphenol A (BPA), a key ingredient of conventional epoxy, is known to interfere with human's natural hormones and cause various disorders in the body system. Reduction or complete elimination of the usage of BPA is therefore high in the agenda of the coatings industries. In this study, a transparent, anti-icing, bio-based epoxy coating was developed for room-temperature processing. As a result of hydrophobic treatment with addition of silanes, the glass-transition temperature and anti-icing performance of bio-based epoxy resin increased significantly. The optimum coating exhibited good water repellency and ice-adhesion strength as low as $50 \mathrm{kPa}$ at $-20^{\circ}$, which was half of the widely accepted threshold value of $100 \mathrm{kPa}$ for icephobic coatings. The icing delay time was much delayed compared with that of an uncoated glass substrate. To further demonstrate the anti-icing performance of the optimized coating, supercooledwater dripping on coated wooden outdoor floors and wooded boards was conducted at $-15^{\circ} \mathrm{C}$, superior antiicing performance was observed on the coated substrates.

\section{Introduction}

Icephobic coatings, as a passive strategy for anti-icing, are essential for a number of applications in cold climate or environment, including e.g. solar cells, windshields of automobiles, outdoor sports facilities,

\footnotetext{
* Corresponding author.

E-mail addresses: wuxi0011@e.ntu.edu.sg (X.Wu), aszchen@ntu.edu.sg (Z. Chen).
}

marine and aerospace structures [1-3]. Earlier studies on icephobic coating were primarily focused on salt-glucose compounds [4], cellulose lacquers [5], liquid monolayers such as hydrocarbons, fluorocarbons, waxes, oil, as well as grease and rubber coatings [6-10]. A rapid development of superhydrophobic coatings in recent years [11] offers new opportunities for the design of icephobic coatings. A notion "icephobic coating" refers to several aspects of an icing event: i) a coating surface should enable water droplets to roll off easily or bounce away before 
icing occurs; ii) there should be a delay in an ice-formation temperature under continuous-cooling conditions, or delay of ice formation at a fixed temperature on an icephobic surface; and iii) in an inevitable situation of ice formation under extremely low temperatures, such ice should be removed with ease. This implies low adhesion strength between the formed ice and the coating surface.

Despite the progresses made in the past decades, major problems still remain, hindering practical applications of icephobic coatings. So far, all the developed solutions for superhydrophobic coatings require improvement in mechanical performance and long-term durability. Microscopic surface roughness or patterns (especially hierarchical structures) give a rise to a high water contact angle and good water repellency, however, such surface could be destroyed easily by mechanical forces encountered during service such as abrasion or erosion [12]. Besides, anti-icing property of superhydrophobic coating was found to be reduced greatly due to water condensation on surface asperities in presence of humidity or pressure $[13,14]$. Recently, slippery liquidinfused porous surfaces, or SLIPS, attracted much attention [15-19]. As reported, SLIPS repel a variety of liquids, including water and some oils, and adhesion of ice is low [20]. However, mechanical properties of SLIPS are low as the functional component is only a layer of infused oil $[2,12]$. An icephobic coating ideally should be mechanically robust, water repellent, with delayed ice-formation time and temperature, and with weak adhesion between ice and substrates. Transparency is another important consideration for icephobic coatings in numerous applications, such as solar cells, windows, curtain wall and windshields of automobiles etc., however, research in this area is still very limited.

Eproxy-based anti-icing coatings have been studied since 1950s [21-23]. Epoxy resin, with a wide range of formulation possibilities in the presence of a curing agent and processing versatilities, is one of the most widely used thermosets thanks to its good mechanical properties, excellent electrical insulating properties, good chemical and thermal resistance, excellent adhesion and processability [24-26]. Diglycidyl ether of bisphenol A (DGEBA), which represents $>90 \%$ of epoxy precursors in the world, is by far the most widely used monomer to formulate epoxy networks [27]. Bisphenol A (BPA) is accounting for $>67 \%$ of the molar mass of DGEBA [28,29]. A driving force for developing of bio-derived epoxides comes from the growing awareness about toxicity of BPA, coupled with the concern of depletion of fossil reserves and greenhouse gas emission. Sustainability and green chemistry are driving the development of next-generation materials and products. Biodegradable and bio-based epoxy products are of great importance as a viable alternative to petroleum-based epoxy coatings, especially in outdoor facilities, marine and aerospace industries. Bio-epoxides derived from natural sources, such as sugar, plant oil and wood became increasingly important as eco-friendly and sustainable products that could replace BPA [24,30-32]. Although considerable efforts were made, bio-based epoxy has not been used for anti-icing coatings. Here, the focus is to develop icephobic coatings using bio-based epoxy resin. Feng et al. reported that the bio-based epoxy picked up at least $4 \%$ moisture in $60 \%$ humid air $[31,33]$. To reduce the moisture uptake of bio-epoxy, we used hydrophobic additives such as Dynasylan ${ }^{\circledR}$ F 8815, Tego ${ }^{\circledR}$ Phobe 1401 and 1505 to offset the intrinsic hydrophilicity of epoxy materials. The fabricated coatings were transparent, spray or dip coatable, scalable, green and eco-friendly. The process was simple, and the coatings could be cured at room temperature. The prepared coatings also exhibited very low ice-adhesion strength $(\sim 50 \mathrm{kPa})$ at $-20^{\circ} \mathrm{C}$, which was well below a criterion for icephobic coatings $(<100 \mathrm{kPa})[34,35]$.

\section{Materials and methods}

\subsection{Materials}

Bio-based epoxy resin (SUPER SAP® 100/1000) was purchased from Entropy Resins, while ethanol (ACS reagent, absolute, 99.8\%) and 3glycidyloxypropyl trimethoxysilane (GLYMO, 99\%) were obtained from Sigma Aldrich. Dynasylan® F 8815, Tego® Phobe 1401 and 1505 were produced by Evonik industries. Microscope glass slides used as substrates were obtained from Sailboat Lab Co., Ltd. Wooden floor plates and wood boards used for supercool water ice formation tests were obtained from IKEA.

\subsection{Synthesis of the E-series of bio-based epoxy coating}

A bio-based epoxy solution was prepared as follows: $1 \mathrm{~g}$ of SUPER SAP ${ }^{\circledR} 100 / 1000$ part $A$ and $1 \mathrm{~g}$ of a hydrophobic additive were mixed into $3 \mathrm{~g}$ of ethanol in a Thinky Mixer rotating at $2000 \mathrm{rpm}$ for $15 \mathrm{~min}$. After that, $8 \mathrm{~g}$ of SUPER SAP ${ }^{\circledR} 100 / 1000$ part B was added in the above mixture and mixed for another $5 \mathrm{~min}$. The prepared bio-based epoxy solutions were spray-coated onto the glass substrates employing an airbrush kit (AS06KB). The obtained fresh coatings were cured at room temperature for $48 \mathrm{~h}$. To investigate anti-icing properties of coatings with different surface energies, three different hydrophobic additives Dynasylan ${ }^{\circledR}$ F 8815, Tego ${ }^{\circledR}$ Phobe 1401 and 1505 were used separately. Dynasylan ${ }^{\circledR} \quad$ F 8815 is a fluoroalkylfunctional water-borne oligosiloxane. Tego® Phobe 1401 is an amino siloxane emulsion, while Tego ${ }^{\circledR}$ Phobe 1505 is an amino functional polysiloxanes. The obtained final samples were denoted as E-8815, E-1401 and E-1505, corresponding to their additives.

\subsection{Synthesis of G-series of bio-based epoxy coating}

To improve bonding strength between bio-epoxy and hydrophobic additives, GLYMO was utilized to replace ethanol, following the same preparation procedure as for the E-series. Briefly, parts A and B of SUPER SAP® 100/1000, GLYMO and one of the hydrophobic additives were mixed with the weight ratio of $1: 8: 3: 1$ and then spray-coated onto substrates. Following the same convention as the E-series, the obtained final samples were named G-8815, G-1401, and G-1505.

\subsection{Characterization and performance evaluation}

The surface topology of the coatings was scanned using an atomic force microscopy (AFM, Asylum Research Cypher S, USA), surface roughness was also recorded from the AFM measurement. The roughness values were the average of at least three measurements obtained at different locations of the coatings. The scanning area was $20 \mu \mathrm{m}$ $\times 20 \mu \mathrm{m}$. A DSC (Q10, TA Instruments) method was utilized to determine glass transition temperatures of coatings. The water contact angle and the sliding angle were measured with a contact angle system (OCA 20, Dataphysics Co., Germany) at different temperatures. The surface energy of coatings was measured following the Owens, Wendt, Rabel and Kalble (OWRK) [36-38] method, in which water and ethylene glycerol were used as polar liquids while diiodomethane was used as a non-polar liquid. The transmittance of the coatings was examined by UV-VIS spectrophotometer (Shimadzu UV-2501PC, Japan).

The icing delay time was measured at $-15^{\circ} \mathrm{C}$ on the cooling plate of the contact angle system. Glass-substrate samples were directly placed on the cooling plate. To obtain supercooled water, $10 \mu$ water droplets were dropped on each sample before cooling. The temperature was held constant at $-15{ }^{\circ} \mathrm{C}$ and the time of freezing of water droplet was recorded using a built-in CCD camera. The icing delay time of the coatings was determined by the time at which the light reflection of the water droplets changed from clear and reflective to blurry and nontransparent. It has to be pointed the choice of $-15{ }^{\circ} \mathrm{C}$ for the icing delay time measurement was mainly based on range of durations required for ice formation. The times taken should neither be too long and laborious (if the temperature is higher) nor too short and difficult to differentiate (if the temperature is lower).

Measurements of ice adhesion strength between an ice block and coating surfaces follows the scheme from our group's previous report [39]. A Teflon mold with an inner diameter of $18 \mathrm{~mm}$ was filled with 
deionized (DI) water, and then covered with a coated substrate on top and was placed in a climate chamber (Cincinnati Sub-Zero environmental chambers, USA) for $24 \mathrm{~h}$ at $-20^{\circ} \mathrm{C}$. We take note that most of the past research reported ice adhesion at $-15{ }^{\circ} \mathrm{C}$. Our current work measured the ice adhesion under a more stringent condition, as there is usually a small increase in the adhesion strength with decreasing testing temperature.

Besides static water droplet behavior, dynamic droplet impacting test was also carried out on the G-series coatings and compared with an uncoated glass substrate (see Supporting information video clip 1). A $10 \mu \mathrm{l}$ water droplet was dripped onto the test surfaces at a distance of $15 \mathrm{~cm}$. Time-sequential digital images of the droplet were recorded by a high speed camera (Vision Research, Phantom micro M120). All tests were carried out at $-15^{\circ} \mathrm{C}$. Furthermore, to simulation a practical application scenario such as outdoor sports/industrial facilities, supercooled deionized (DI) water was dripped onto sample surfaces at -15 ${ }^{\circ} \mathrm{C}$ inside the climate chamber. Coated and uncoated wooden floor plates and wood boards were placed in the chamber at an angle of $60^{\circ}$ to the horizontal plane. The supercooled DI water was prepared by storing it in a refrigerator at $-5{ }^{\circ} \mathrm{C}$ before use. The dripping lasted for $5 \mathrm{~min}$ (see Supporting information video clip 2). After which, visual inspection was made on the severity of ice accumulation on the tested surfaces.

\section{Results and discussion}

3.1. Effect of hydrophobic additive on the glass transition temperatures and water contact angles

The glass transition temperature $\left(\mathrm{T}_{\mathrm{g}}\right)$ of bio-based epoxy resin is lower than that of conventional petroleum-based epoxy [31,40]. The depressed $\mathrm{T}_{\mathrm{g}}$ relates to bio-precursor's high affinity with water. To verify the effect of the hydrophobic additives, $T_{g}$ of the bio-based epoxy coatings was tested. Fig. 1 shows the results for E-series and G-series coatings. Higher $\mathrm{T}_{\mathrm{g}}$ than that of the bio-based epoxy matrix was obtained for coatings containing Dynasylan $®$ F 8815 and Tego $®$ Phobe 1505. Addition of Tego ${ }^{\circledR}$ Phobe 1401 decreased $\mathrm{T}_{\mathrm{g}}$ of the bio-based epoxy matrix. It is well-known that glass transition temperature is related to crosslinking in materials. Dynasylan ${ }^{\circledR}$ F 8815 is a fluoroalkyl functional siloxane, Tego ${ }^{\circledR}$ Phobe 1401 is an amino siloxane emulsion, and Tego ${ }^{\circledR}$ Phobe 1505 is an amino functional polysiloxane. Dynasylan ${ }^{\circledR}$ F 8815 and Tego ${ }^{\circledR}$ Phobe 1505 have functional groups; hence, they can more easily cross-link with various components of the coating system than Tego ${ }^{\circledR}$ Phobe 1401 . By comparing $\mathrm{T}_{\mathrm{g}}$ of $\mathrm{G}$-series and E-series coatings, it was found that the former coatings exhibited higher $\mathrm{T}_{\mathrm{g}}$ than the latter. This is due to silanization of GLYMO, hydrophobic additives and the biobased epoxy matrix. The process of silanization of GLYMO with

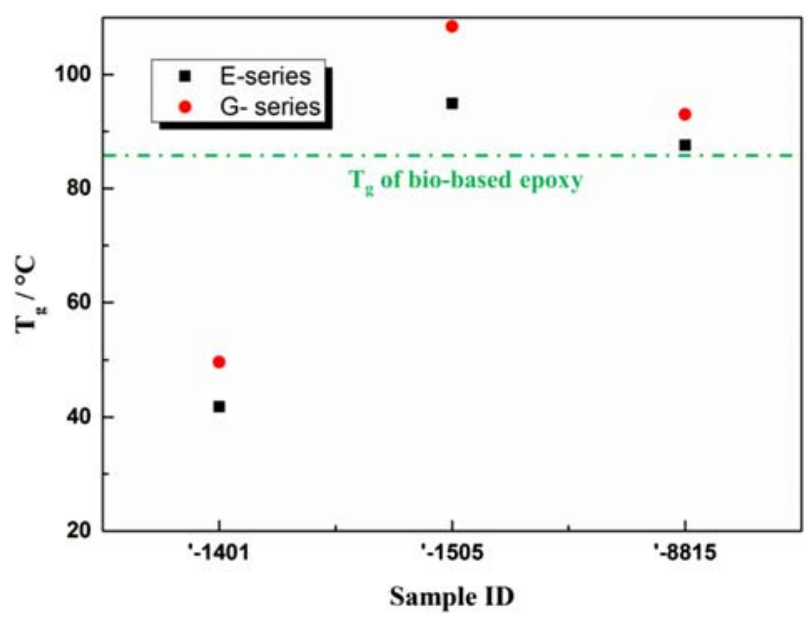

Fig. 1. Glass transition temperatures of E-series and G-series coatings. hydroxyl groups of the bio-based epoxy resin increased their hydrophobicity of the bio-based epoxy resin. Beside, GLYMO as an alkoxysilane molecule improved bonding strength between bio-epoxy and hydrophobic additives. Hu's group reported that after incorporating GLYMO and other silanes in epoxy resin, the water-uptake of epoxy coatings decreased remarkably $[41,42]$. This description agrees well with our experiment results.

A coating with higher $\mathrm{T}_{\mathrm{g}}$ has lower permeability of oxygen and water molecules, leading to higher water resistance. Fig. 2 shows the water contact angles and the sliding angles of E-series and G-series coatings. The G-series coatings exhibited higher water contact angles and lower sliding angles than E-series coatings. For the latter, only E-1505 coatings displayed a water sliding angle (but it is much higher than the one for G1505 - Fig. 2b). $10 \mu \mathrm{l}$ water droplet could not slide down from the other two coatings, indicating a dominant Wenzel wetting mode with a high resistance of water-solid contact line. While the G-series coatings demonstrated remarkably different wetting properties, water droplets slid down easily at a tilt angle $<10^{\circ}$, displaying a dominant Cassie nonwetting state. The difference between the wetting mode and the nonwetting one is distinguished by the pining/non-pining of a solid/air/liquid three-phase contact line. The non-wetting state of a three-phase contact line is accompanied by a change in its active surface area. A water droplet could slide down a non-wetting surface due to the gravity force, overcoming the capillary force. For the G-series, the capillary force between a water droplet and coating surfaces as well as the viscosity force of the water droplet were lower than the gravity force due to the low surface energy (discussed later), thus there was no pining of the three-phase contact line.

\subsection{Anti-icing performance of coatings with bio-based epoxy}

Wetting behavior of surfaces greatly affects the icephobicity. Fig. 3 presents ice-adhesion strength of E-series and G-series coatings at $-20^{\circ} \mathrm{C}$. A dramatic and highly significant reduction in ice-adhesion strength of coatings was observed by replacing ethanol with GLYMO. A water-repellent coating exhibits lower permeability of oxygen and water molecules. Obviously, a smaller number of water molecules mean fewer hydrogen bonds between ice and coating surfaces. Due to the low glass transition temperature and poor water repellency, more hydrogen bonds formed between ice and the E-series coating surfaces. This induced formation of a layer of ice firmly attached to the coating surface, leading to a higher force necessary to overcome the adhesion force. On the contrary, lower moisture absorption of the G-series coatings led to less anchoring ice, exhibiting significantly lower iceadhesion strength.

It was noted that coatings with Tego® Phobe 1505 displayed higher $\mathrm{T}_{\mathrm{g}}$ and higher hydrophobicity, leading to lower ice-adhesion strength than that of two other hydrophobic additives. One possible reason is that Tego ${ }^{\circledR}$ Phobe 1505 is an amino functional polysiloxanes with longer chains. This is consistent with the previous findings [11], in with longer chains exhibiting higher hydrophobicity, and being more water repellent.

Comparing the two coating systems, a clear trend can be observed about the superior performance of the silane grafted bio-based epoxy coatings as compared to the E-series coatings. Therefore, in the subsequent study, we will focus on the G-series samples because of their better overall performance in ice adhesion, rolling off angle, and thermal stability.

Fig. 4 shows the icing delay time of different G-series samples and compared with an uncoated glass substrate. It took $3 \mathrm{~min}$ and $17 \mathrm{~s}$ for the temperature for all substrates to reach $-15^{\circ} \mathrm{C}$. The droplet on uncoated glass surface started to freeze first after $54 \mathrm{~s}$, followed by the G-1401 coating (60 s) and G-8815 coating (70 s). The G-1505 coating demonstrated a much longer freezing delay than the above samples: ice nucleation in the water droplet on this coating occurred at around $6^{\prime} 02^{\prime \prime}$ (icing delay of $165 \mathrm{~s}$ after the temperature reached $-15^{\circ} \mathrm{C}$ ). 

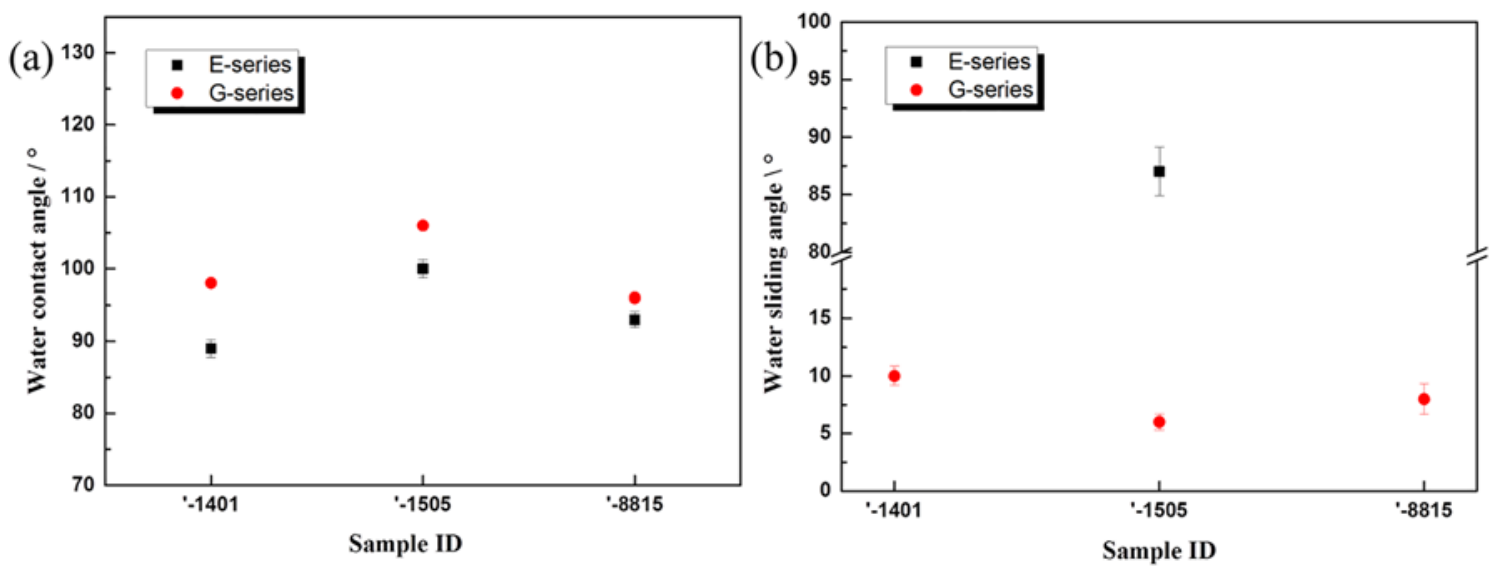

Fig. 2. Water contact angles (a) and sliding angles (b) of E-series and G-series coatings.

Recent studies indicate that icephobicity of a surface is dominated by water repellency, which is greatly affected by surface characteristics [2, 43]. Here, the effect of surface morphology on the anti-icing performances is analysed. 3D surface roughness and apparent surface energy of the $\mathrm{G}$-series coatings are shown in Fig. 5 . A surface of the G-1401 coating with a convex-concave micro-structure had the highest magnitudes of surface roughness and apparent surface energy than other two surfaces. A surface of the G- 1505 coating primarily presented a regular convex microstructure with few concave structures. In addition, it exhibited the lowest apparent surface energy among the tested coatings. The G8815 coating demonstrated a neatly flat surface with some large protrusions (these protrusions lead to a similar roughness reading as the G1505 coating - Fig. 5d). Apparently, the G-1505 coatings showed much higher water resistance than the G-8815 coatings with similar surface roughness because of its microstructure and lower apparent surface energy. This difference implies that a structured surface with low surface energy is preferred for anti-icing as it allows air to be trapped between the surface and the water droplet.

It is well-known that a decrease of temperature induces condensation of moist in air on the coating surface, leading to extension of the air-liquid-solid contact line. Fletcher reported [44] that the nucleation process was very sensitive to changes of air-liquid-solid interfacial energy. The extension of the contact line greatly increased the interfacial energy, promoting ice nucleation. Fig. 6 shows water wettability of Gseries coatings at different temperatures. The water wettability of G1401 coating surfaces changed significantly as the temperature of samples decreased due to the serious moisture condensation. The highly rough surface of the G-1401 coating was fully wetted at low

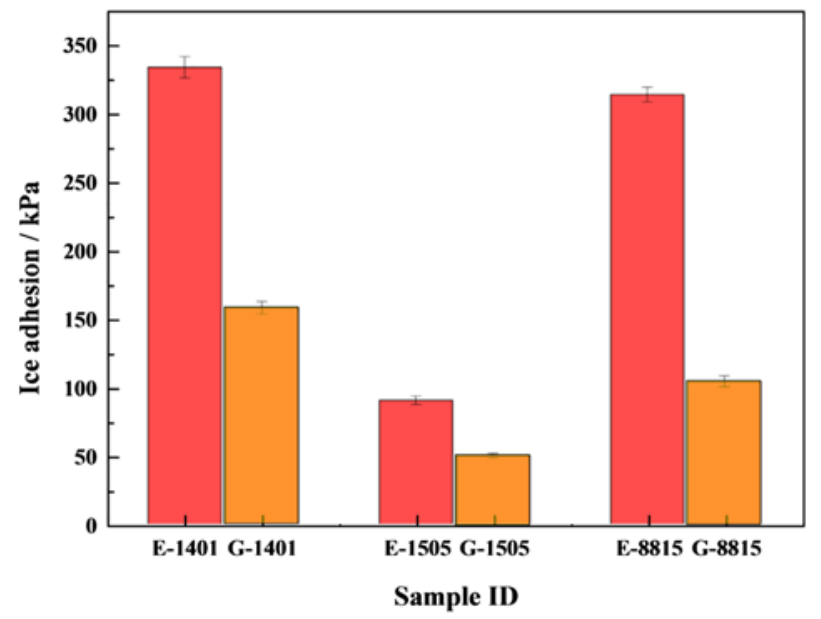

Fig. 3. Ice adhesion strength of E-series and G-series coatings at $-20{ }^{\circ} \mathrm{C}$. temperatures due to the relatively higher apparent surface energy, exhibiting a significant decrease in water contact angle and water sliding angles as the temperature decreased. No sliding motion of a $10 \mu \mathrm{l}$ water droplet on the G-8815 coating was observed when the temperature of the sample reached $-15^{\circ} \mathrm{C}$ or bellow. However, the coating presented better water-shielding ability than the G-1401 coating due to its higher $T_{g}$, lower surface roughness and surface energy. The best watershielding effect was observed on the G-1505 coating.

Although a slight decrease in the water contact angle and an increase in the water sliding angle were observed as the temperature decreased; a supercooled water droplet slid down the G-1505 coating surface easily at $-15^{\circ} \mathrm{C}$, indicating its good water repellency. Similar correlation was found by Fu et al. [39] between good water repellency at low temperatures and ice adhesion. Yoshimitsu et al. [45] explained the importance of the three-phase contact line for the water-shedding property. Our study confirmed that the three-phase contact line evolution during the cooling process was a good indication of the water repellency at low temperatures. The G-1401 coating was able to maintain a partial wetting state only at room temperature. The G-8815 coating was able to keep a partial wetting state at $-10{ }^{\circ} \mathrm{C}$, while the $\mathrm{G}-1505$ coating at $-15^{\circ} \mathrm{C}$. When the water froze, air trapped on partially wet surfaces decreased bonding strength between the ice and the coating surface, leading to lower ice-adhesion strength. Besides, the heat transfer rate between the supercooled water and the surface decreased due to the trapped air. This also led to a longer icing delay and a lower icenucleation temperature. In the current study, the G-1505 coating presented less condensation than two other coatings and indicated a minimum temperature impact on the extension of the three-phase contact line, resulting in a longer icing delay than the other two coatings. Furthermore, the delay time was very sensitive to the surface geometry. Researchers investigated the effect of the surface geometry on a freeenergy barrier of ice nucleation, and proved that nucleation on a concave surface was easier than on flat and convex ones [46,47]. The longer icing delay of the $\mathrm{G}-1505$ coating can also be partially contributed by its convex surface features.

Besides the static water resistance, the dynamic behavior of water droplet impacting on the coating surfaces was also investigated at $-15^{\circ} \mathrm{C}$ (see Supporting information video clip 1). The droplet deformation during spreading and retracting process was analysed and compared with that of an uncoated glass substrate. Fig. 7(a) shows the spreading factor, $\xi=D / D_{0}$, of the uncoated glass substrate and the G-series coatings, where $D=D(t)$ is the droplet contact diameter on the tested surface at time $t$ (in $\mathrm{ms}$ ) and $D_{0}$ is the initial droplet diameter. When the droplet touched the tested surfaces, it spread rapidly on these surfaces. Nearly no retracting was observed on the uncoated glass surface due to its hydrophilicity, and this result is consistent with reported literatures. The spreading factors of the $\mathrm{G}$-series coatings increased rapidly first then decreased, and the droplet contact diameter oscillated 


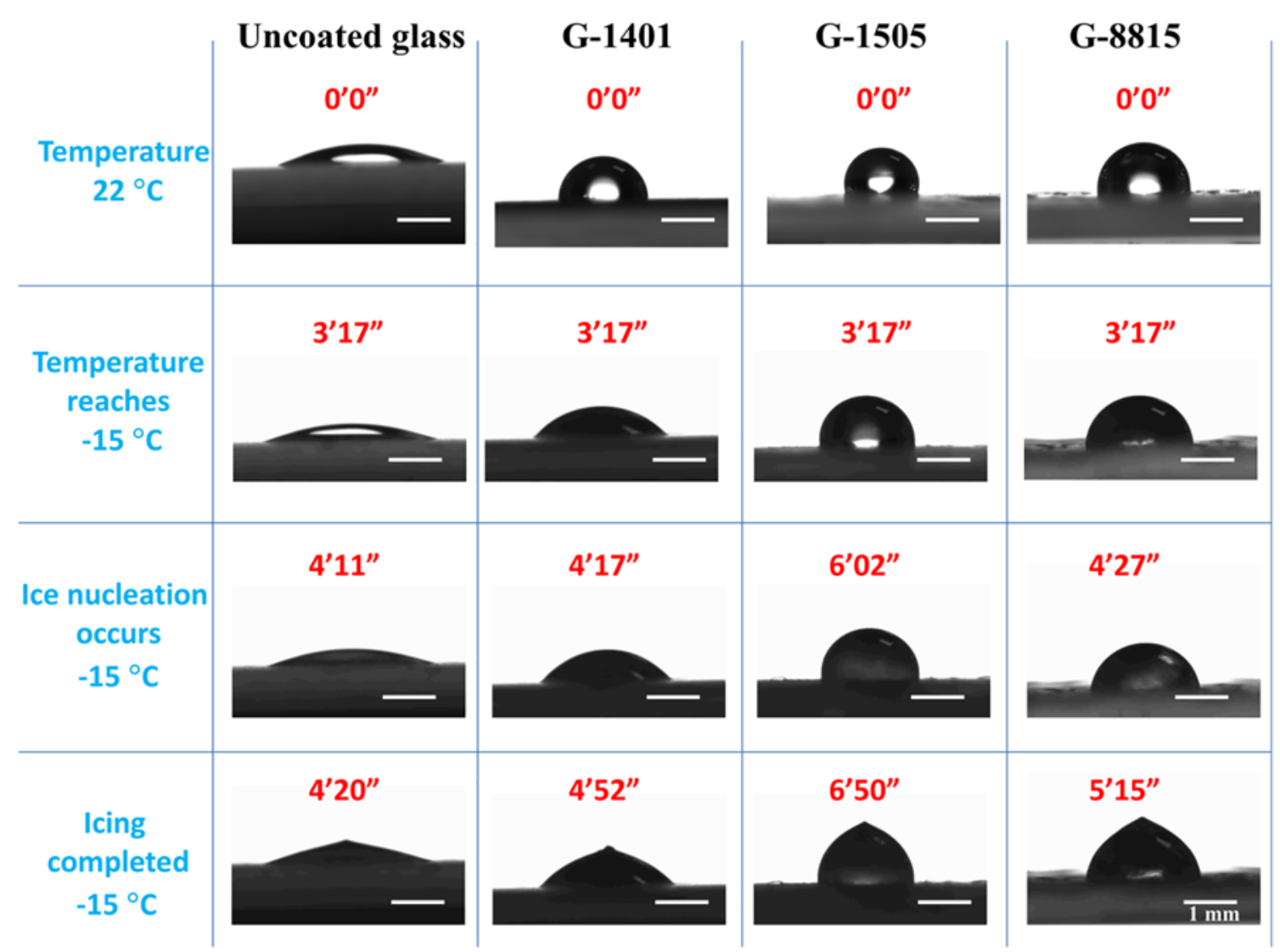

Fig. 4. Icing delay time for an uncoated glass surface and G-series coatings at $-15^{\circ} \mathrm{C}$.

(a)

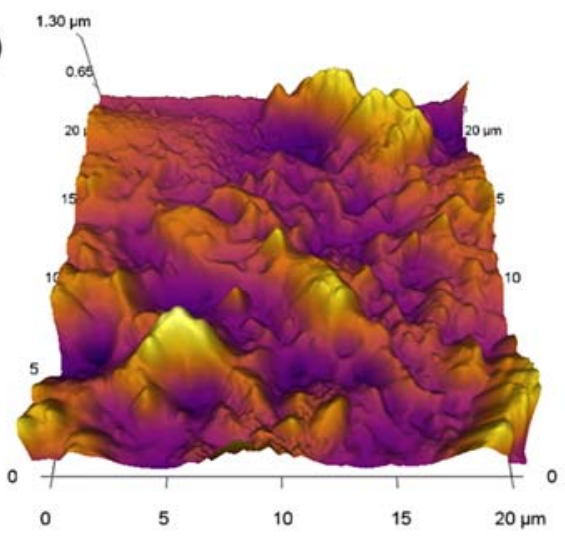

(c)
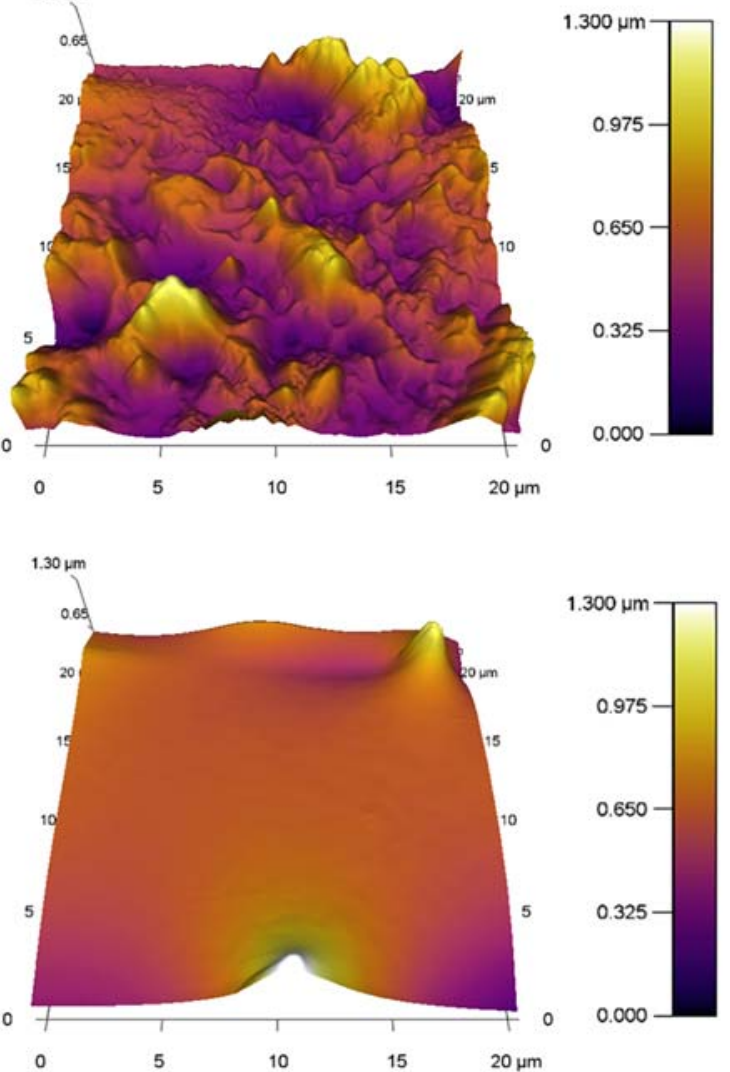

(b)
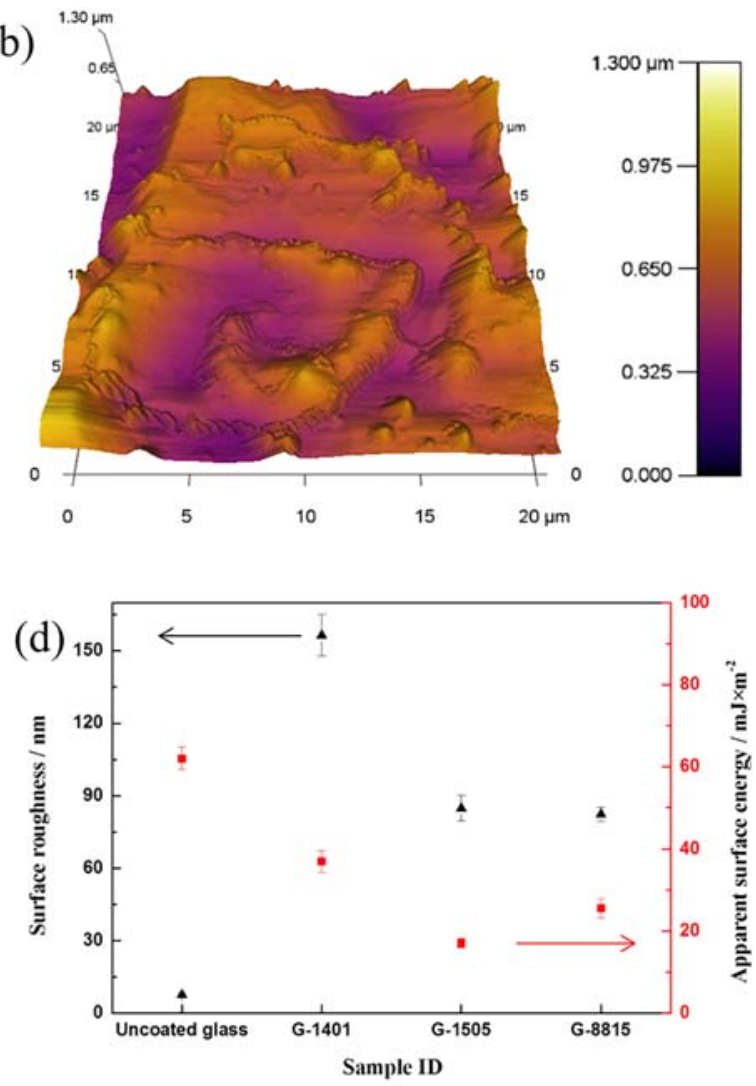

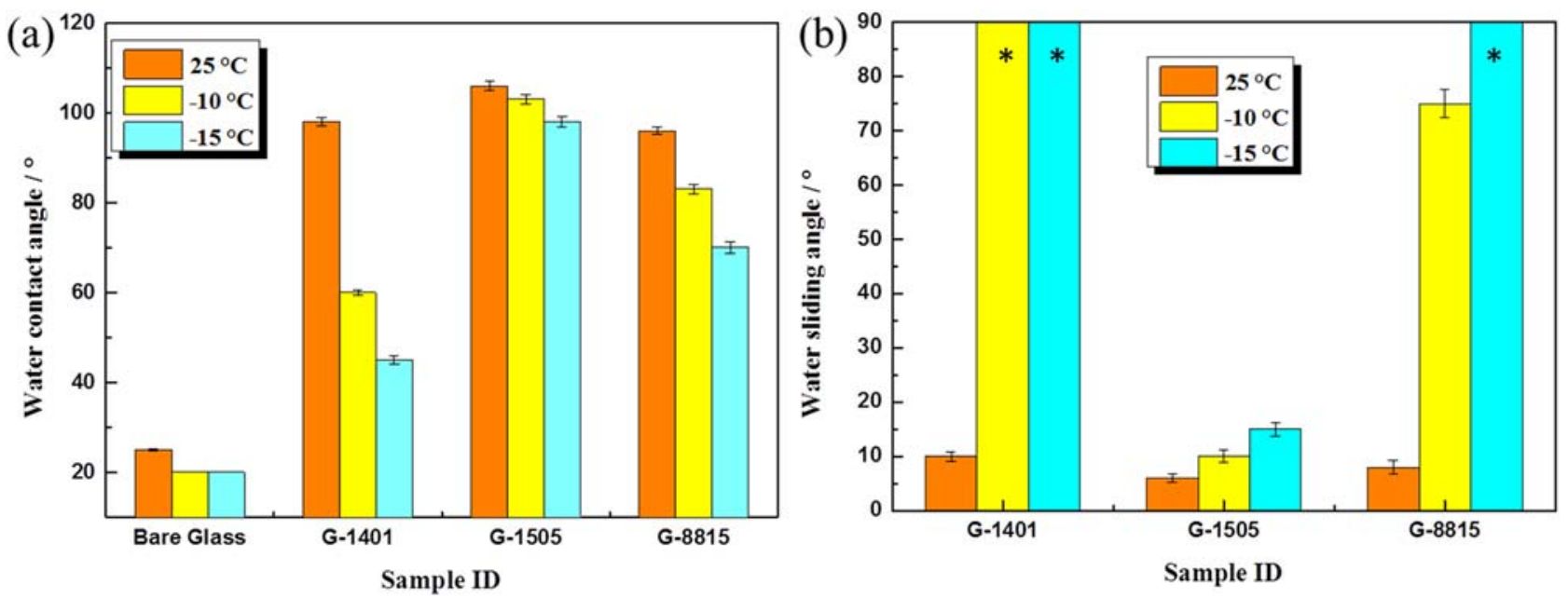

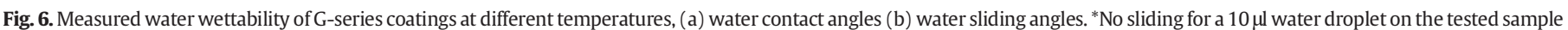
surface up to a tilt angle of $90^{\circ}$.

until a steady state was reached. The smallest retraction diameter among the G-series coatings was observed on the G-1505 surface, consistent with its good static water repellency. Although the retracting process was observed on the G-series coating surfaces, no bouncing of the water droplet was observed. This is significantly different from the widely reported behavior of superhydrophobic coatings, and this observation can be explained by the relatively low water contact angle of the coatings ( $\sim 100^{\circ}$, see Fig. 2 ), and a larger water-solid contact area. However, despite that no bouncing was observed, the low ice-adhesion strengths of the G-series coatings enable the inevitably formed ice be easily removed from the surface.

To further compare the dynamic droplet impact behavior of the uncoated glass substrate and the G-series coatings, the water mobility parameter $\xi_{\min } / \xi_{\max }$, defined as the ratio of minimum droplet diameter $D_{\text {min }}$ over the maximum $D_{\text {max }}$, is shown in Fig. 7(b). The G-1505 surface presented the lowest $\xi_{\min } / \xi_{\max }$ (i.e., the highest water mobility) and the uncoated glass substrates exhibited the highest $\xi_{\min } / \xi_{\max }$ (i.e., the lowest water mobility). The insets are time-sequential images of water droplet impacting on the G-1505 surface before touching $\left(D_{0}\right)$, at the maximum droplet spreading diameter $\left(D_{\max }\right)$, and at the minimum droplet retracting diameter $\left(D_{\min }\right)$. The inset top-view image was taken on the G-1505 surface at $D_{\min }$. It is noted that the G-1401 surface presented slightly better retracting behavior (see Fig. 7(a)) and higher dynamic water mobility (see Fig. 7(b)) than the G-8815 surface. This may be due to the large protrusions on the G-8815 surface which has similar function as flood resistant piles that reduce the cohesive force of the droplet and increase the energy dissipation. Since the G-1505 surface presented the best water repellency at low temperature, the longest icing delay time and the lowest ice-adhesion strength, further study will be focused on the G-1505 samples.

\subsection{Transmittance of the $G-1505$ coating}

The transmittance of the G-1505 coating coated and uncoated glass slide is given in Fig. 8. Although the glass slide coated with G-1505 coating exhibited a slightly decrease in transmittance, it still exhibited transmittance as high as $81 \%$. Due to partial reflections between the interface and various surfaces, precise calculation of two-layer transmittance is complicated and transfer matrix is needed for the modelling. To simplify the analysis, a first approximation is assumed, and the resultant transmittance $T$ of the coated glass slide is given by

$T=T_{g} \cdot T_{C}$
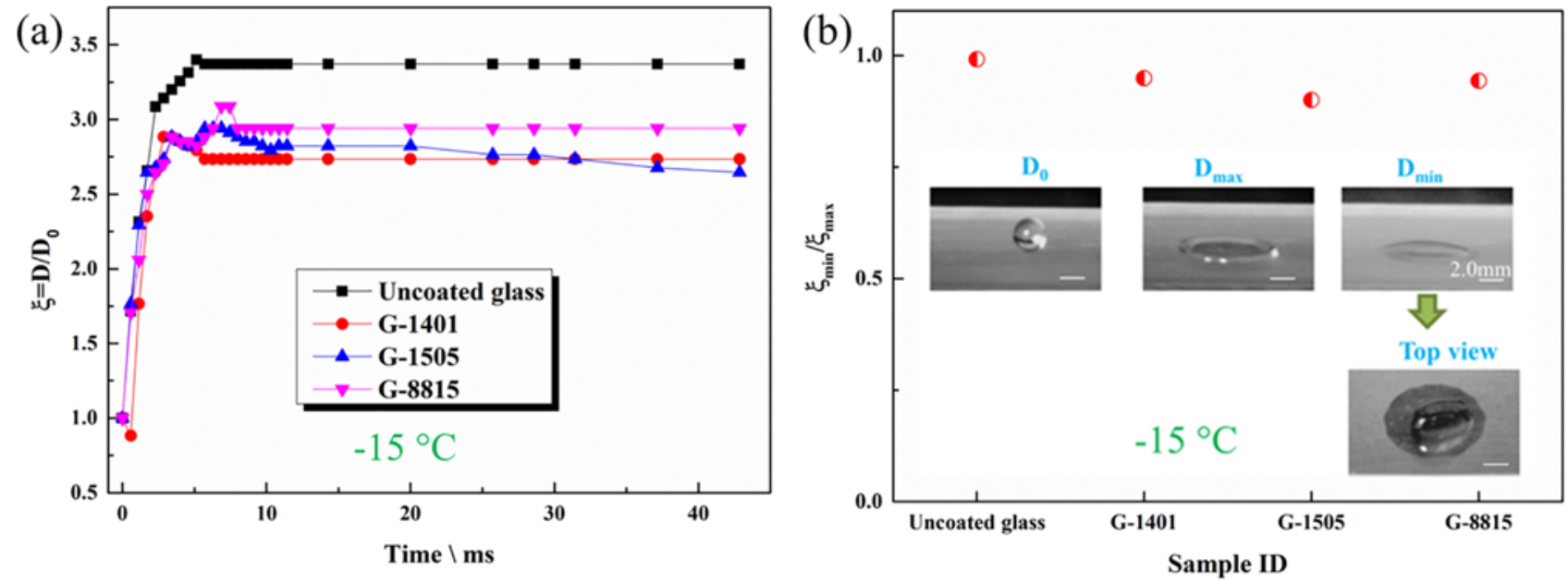

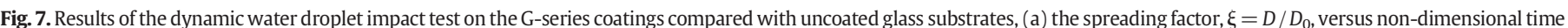

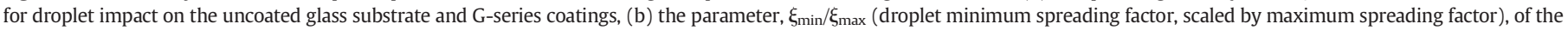

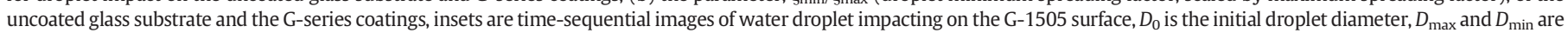
the maximum droplet spreading diameter and the minimum droplet retracting diameter, respectively. 


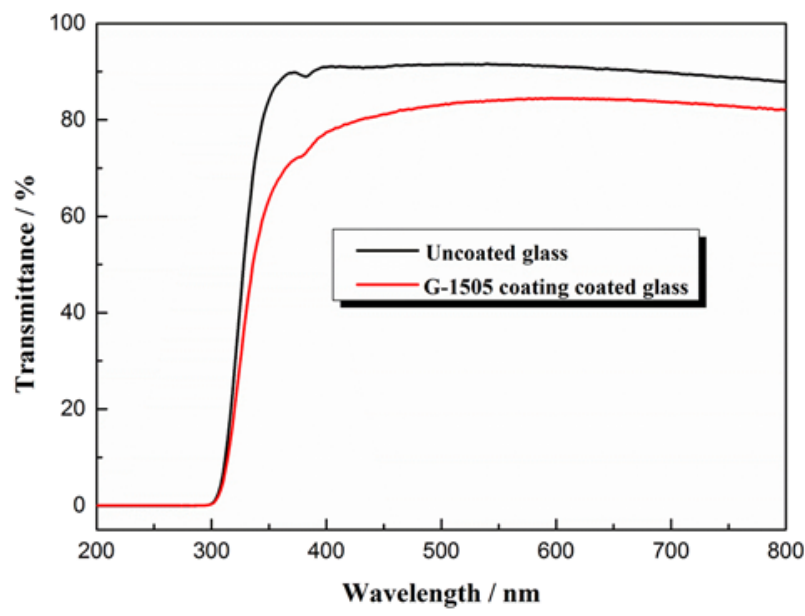

Fig. 8. Transmittance of the G-1505 coating coated and uncoated glass slides.

where $T, T_{g}$ and $T_{c}$ are transmittance of the G-1505 coating coated glass slide, the glass slide and the G-1505 coating, respectively. Wavelength at $550 \mathrm{~nm}$ was chosen for this calculation and the G-1505 coating possessed transparency as high as $92.0 \%$.

\subsection{Ice accumulation study on $\mathrm{G}-1505$ coated wooden surfaces}

To demonstrate the anti-icing properties of the G-1505 coatings, the coatings on a wooden floor plate and a wood board were prepared. It can be seen that there is nearly no appearance change on the coated substrates as shown in Fig. 9. As described in Section 2.4, supercooledwater dripping test was carried out on these coatings (see Supporting information video clip 2). Fig. 9 shows images after the ice accumulation test on the coated and uncoated wooden floor plates and the wood boards. Residual ice was seen after the accumulation test on the uncoated surfaces (marked with blue rectangles). In contrast, no residual ice could be found on the coated sides of the wooden floor plates and the wood boards, indicating their good water repellency and anti-icing properties.

\section{Conclusions}

Transparent and eco-friendly anti-icing coatings based on a bioepoxy resin were successfully developed using hydrophobic additives and silanes. As a result of hydrophobic interactions, coating with different hydrophobic additives exhibited different water repellency and anti-icing performance. The addition of silanes enhanced the water repellency and reduced ice adhesion strength. The optimum coating based on bio-epoxy exhibited good water repellency and ice adhesion as low as $50 \mathrm{kPa}$ at $-20^{\circ} \mathrm{C}$, well below the widely accepted threshold value of $100 \mathrm{kPa}$ for icephobic coatings. It is demonstrated that coatings exhibited different wetting behavior at different temperatures; the change of water repellency at a low temperature affected the antiicing performance of coatings. The dynamic water repellency of coatings was also studied, and the coated surfaces displayed better water droplet retraction and mobility than uncoated surface at low temperature. The anti-icing performance was demonstrated for the optimized coating on wooden floor plates and wood boards. There was nearly no ice accumulation on the coated surface. The developed anti-icing coating method can be potentially scaled up to various industrial applications, making them suitable for outdoor structures in cold climate.

Supplementary data to this article can be found online at https://doi. org/10.1016/j.matdes.2017.12.017.

\section{Acknowledgment}

Financial support from Nanyang Technological University in form of a research scholarship, and the Agency for Science, Technology and Research (A*STAR) of Singapore (SERC 1528000048) is gratefully acknowledged.
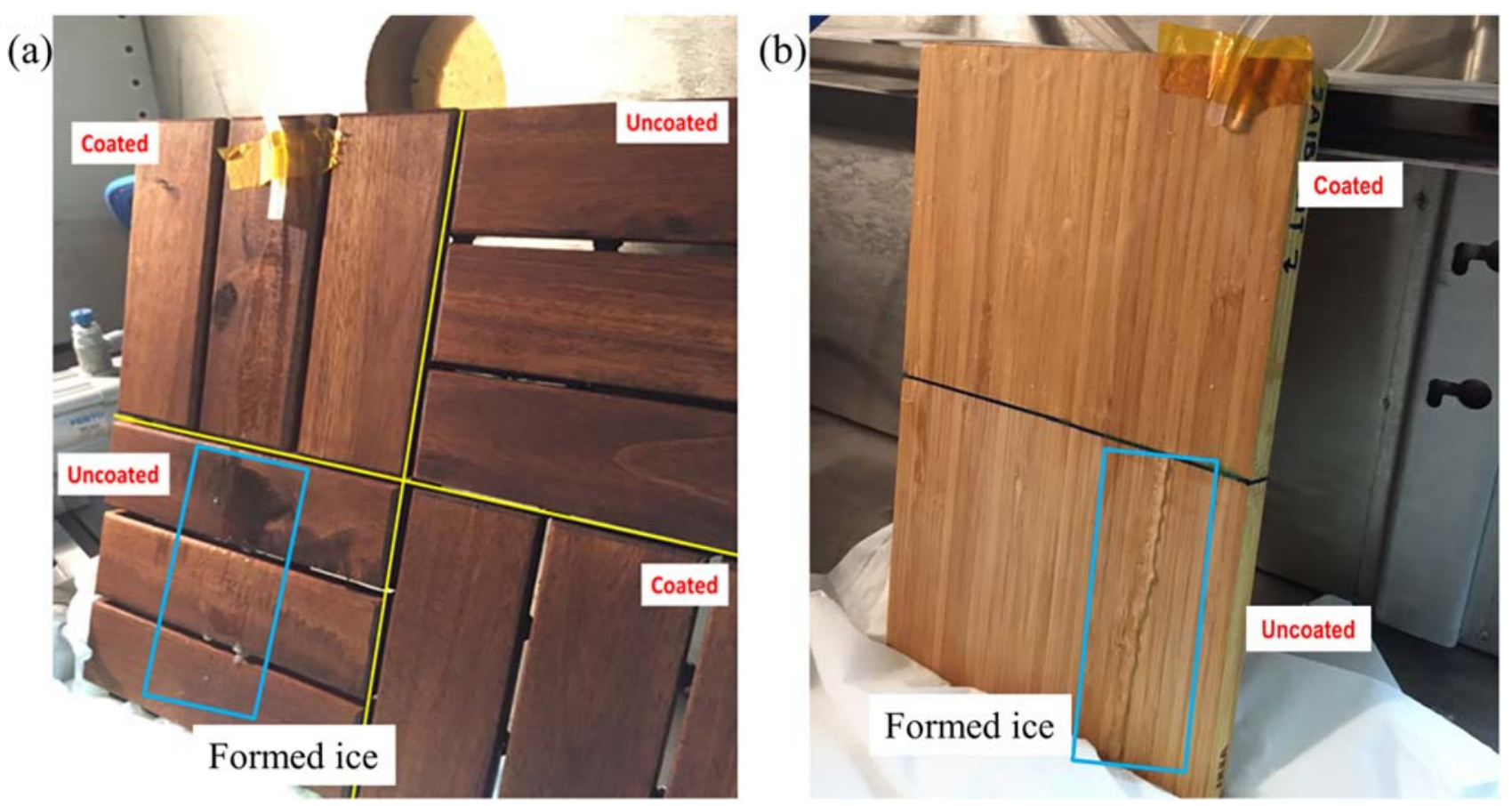

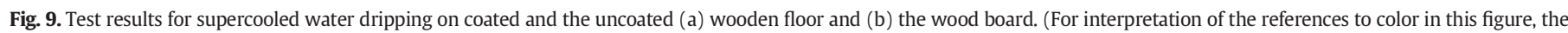
reader is referred to the web version of this article.) 


\section{References}

[1] M. Nosonovsky, V. Hejazi, Why superhydrophobic surfaces are not always icephobic, ACS Nano 6 (2012) 8488-8491.

[2] M.J. Kreder, J. Alvarenga, P. Kim, J. Aizenberg, Design of anti-icing surfaces: smooth, textured or slippery? Nat. Rev. Mater. 1 (2016) 15003.

[3] Y. Shen, J. Tao, H. Tao, S. Chen, L. Pan, T. Wang, Anti-icing potential of superhydrophobic Ti6Al4V surfaces: ice nucleation and growth, Langmuir 31 (2015) 10799-11806.

[4] Lewis CA. Antifreezing compound. U.S. Patent 1,282,249; 1918

[5] C.J. Rolle, W.D. Barnes, Cellulose lacquers-de-icing lacquer for stationary aircraft, Ind Eng. Chem. 48 (1956) 1326-1327.

[6] J.R. Saroyan, Coatings and encapsulants-preservers in the sea, Ocean Eng. 1 (1969) 435-446 (IN27-IN38, 477-456).

[7] L.O. Andersson, C.G. Golander, S. Persson, Ice adhesion to rubber materials, J. Adhes. Sci. Technol. 8 (1994) 117-132.

[8] H.G. Lake, An investigation of the problem of ice removal from B-29 radomes, DTIC Document, 1952.

[9] J.M. Sayward, Seeking low ice adhesion, DTIC Document, 1979

[10] H. Jellinek, Ice adhesion, Can. J. Phys. 40 (1962) 1294-1309.

[11] J. Genzer, K. Efimenko, Creating long-lived superhydrophobic polymer surfaces through mechanically assembled monolayers, Science 290 (2000) 2130-2133.

[12] L. Bocquet, E. Lauga, A smooth future? Nat. Mater. 10 (2011) 334-337.

[13] S. Jung, M. Dorrestijn, D. Raps, A. Das, C.M. Megaridis, D. Poulikakos, Are superhydrophobic surfaces best for icephobicity? Langmuir 27 (2011) 3059-3066.

[14] M.A. Sarshar, C. Swarctz, S. Hunter, J. Simpson, C.H. Choi, Effects of contact angle hysteresis on ice adhesion and growth on superhydrophobic surfaces under dynamic flow conditions, Colloid Polym. Sci. 291 (2012) 427-435.

[15] T.S. Wong, S.H. Kang, S.K. Tang, E.J. Smythe, B.D. Hatton, A. Grinthal, J. Aizenberg, Bioinspired self-repairing slippery surfaces with pressure-stable omniphobicity, Nature 477 (2011) 443-447.

[16] P. Kim, T.S. Wong, J. Alvarenga, M.J. Kreder, W.E. Adorno-Martinez, J. Aizenberg, Liquid-infused nanostructured surfaces with extreme anti-ice and anti-frost performance, ACS Nano 6 (2012) 6569-6577.

[17] J. Chen, R. Dou, D. Cui, O. Zhang, Y. Zhang, F. Xu, X. Zhou, J. Wang, Y. Song, L. Jiang Robust prototypical anti-icing coatings with a self-lubricating liquid water layer between ice and substrate, ACS Appl. Mater. Interfaces 5 (2013) 4026-4030.

[18] L. Zhu, J. Xue, Y. Wang, Q. Chen, J. Ding, Q. Wang, Ice-phobic coatings based on silicon-oil-infused polydimethylsiloxane, ACS Appl. Mater. Interfaces 5 (2013) 4053-4062.

[19] S.B. Subramanyam, K. Rykaczewski, K.K. Varanasi, Ice adhesion on lubricantimpregnated textured surfaces, Langmuir 29 (2013) 13414-13418.

[20] N. Vogel, R.A. Belisle, B. Hatton, T.S. Wong, J. Aizenberg, Transparency and damage tolerance of patternable omniphobic lubricated surfaces based on inverse colloidal monolayers, Nat. Commun. 4 (2013) 2167.

[21] A. ChemWorx, C. Archives, A. Photonics, Special features I/EC annual reviews, Ind. Eng. Chem. 52 (1960) 41A-70A.

[22] V. La Saponara, Environmental and chemical degradation of carbon/epoxy and structural adhesive for aerospace applications: Fickian and anomalous diffusion, $\mathrm{Ar}$ rhenius kinetics, Compos. Struct. 93 (2011) 2180-2195.

[23] B. McDonald, H. Shahsavan, B. Zhao, Biomimetic micro-patterning of epoxy coatings for enhanced surface hydrophobicity and low friction, Macromol. Mater. Eng. 299 (2014) 237-247.

[24] P.Y. Kuo, M. Sain, N. Yan, Synthesis and characterization of an extractive-based bioepoxy resin from beetle infested Pinus contorta bark, Green Chem. 16 (2014) 3483-3493.

[25] C. Aouf, H. Nouailhas, M. Fache, S. Caillol, B. Boutevin, H. Fulcrand, Multifunctionalization of gallic acid. Synthesis of a novel bio-based epoxy resin, Eur. Polym. J. 49 (2013) 1185-1195.
[26] L.B. Manfredi, H. De Santis, A. Vázquez, Influence of the addition of montmorillonite to the matrix of unidirectional glass fibre/epoxy composites on their mechanical and water absorption properties, Compos. A: Appl. Sci. Manuf. 39 (2008) 1726-1731.

[27] J.M. Raquez, M. Deléglise, M.F. Lacrampe, P. Krawczak, Thermosetting (bio) materials derived from renewable resources: a critical review, Prog. Polym. Sci. 35 (2010) 487-509

[28] S. Ma, X. Liu, Y. Jiang, Z. Tang, C. Zhang, J. Zhu, Bio-based epoxy resin from itaconic acid and its thermosets cured with anhydride and comonomers, Green Chem. 15 (2013) 245-254

[29] S. Cousinet, A. Ghadban, I. Allaoua, F. Lortie, D. Portinha, E. Drockenmuller, J.P. Pascault, Biobased vinyl levulinate as styrene replacement for unsaturated polyester resins, J. Polym. Sci. A Polym. Chem. 52 (2014) 3356-3364.

[30] M. Chrysanthos, J. Galy, J.P. Pascault, Preparation and properties of bio-based epoxy networks derived from isosorbide diglycidyl ether, Polymer 52 (2011) 3611-3620.

[31] X. Feng, A.J. East, W.B. Hammond, Y. Zhang, M. Jaffe, Overview of advances in sugarbased polymers, Polym. Adv. Technol. 22 (2011) 139-510.

[32] H. Kishi, A. Fujita, H. Miyazaki, S. Matsuda, A. Murakami, Synthesis of wood-based epoxy resins and their mechanical and adhesive properties, J. Appl. Polym. Sci. 102 (2006) 2285-2292.

[33] G. Busto, P. Saini, X. Feng, W. Hammond, A. East, M. Jaffe, Controlling water uptake of sugar based epoxy resins, Bioengineering Conference (NEBEC), 2011 IEEE 37th Annual Northeast, IEEE 2011, pp. 1-2.

[34] V. Hejazi, K. Sobolev, M. Nosonovsky, From superhydrophobicity to icephobicity: forces and interaction analysis, Sci. Rep. 3 (2013) 2194.

[35] K. Golovin, S.P. Kobaku, D.H. Lee, E.T. DiLoreto, J.M. Mabry, A. Tuteja, Designing durable icephobic surfaces, Sci. Adv. 2 (2016), e1501496.

[36] D. Kaelble, Dispersion-polar surface tension properties of organic solids, J. Adhes. 2 (1970) 66-81.

[37] D.K. Owens, R. Wendt, Estimation of the surface free energy of polymers, J. Appl. Polym. Sci. 13 (1969) 1741-1747.

[38] W. Rabel, Einige Aspekte der Benetzungstheorie und ihre Anwendung auf die Untersuchung und Veränderung der Oberflächeneigenschaften von Polymeren, Farbe Lack 77 (1971) 997-1006.

[39] Q. Fu, X. Wu, D. Kumar, W.C. Ho, D.P. Kanhere, N. Srikanth, E. Liu, P. Wilson, Z. Chen, Development of sol-gel icephobic coatings: effect of surface roughness and surface energy, ACS Appl. Mater. Interfaces 6 (2014) 20685-20692.

[40] F. Xianhon, R. DeMartino, A. East, W. Hammond, M. Jaffe, Synthesis and characterization of isosorbide derived polyols as highly effective humectants. Bioengineering conference, Proceedings of the 2010 IEEE 36th Annual Northeast 2010, pp. 1-2.

[41] W.G. Ji, Hu JM, J.Q. Zhang, C.N. Cao, Reducing the water absorption in epoxy coatings by silane monomer incorporation, Corros. Sci. 48 (2006) 3731-3739.

[42] W.G. Ji, Hu JM, L. Liu, J.Q. Zhang, C.N. Cao, Water uptake of epoxy coatings modified with $\gamma$-APS silane monomer, Prog. Org. Coat. 57 (2006) 439-443.

[43] X. Wu, Q. Fu, D. Kumar, J.W.C. Ho, P. Kanhere, H. Zhou, Z. Chen, Mechanically robust superhydrophobic and superoleophobic coatings derived by sol-gel method, Mater. Des. 89 (2016) 1302-1309.

[44] N. Fletcher, Size effect in heterogeneous nucleation, J. Chem. Phys. 29 (1958) 572-576.

[45] Z. Yoshimitsu, A. Nakajima, T. Watanabe, K. Hashimoto, Effects of surface structure on the hydrophobicity and sliding behavior of water droplets, Langmuir 18 (2002) 5818-5822.

[46] S.J. Cooper, C.E. Nicholson, J. Liu, A simple classical model for predicting onset crystallization temperatures on curved substrates and its implications for phase transitions in confined volumes, J. Chem. Phys. 129 (2008).

[47] D. Xu, W.L. Johnson, Geometric model for the critical-value problem of nucleation phenomena containing the size effect of nucleating agent, Phys. Rev. B 72 (2005), 052101. 